\title{
Pyrrolnitrin Delays Postharvest Fruit Rot in Strawberries
}

\author{
F. Takeda ${ }^{1}$, W.J. Janisiewicz ${ }^{2}$, J. Roitman ${ }^{3}$, N. Mahoney ${ }^{4}$, and \\ F.B. Abeles \\ U. S. Department of Agriculture, Agricultural Research Service, \\ Appalachian Fruit Research Station, 45 Wiltshire Road, Kearneysville, \\ WV 25430
}

Additional index words. storage, biocontrol, gray mold, rhizopus rot, Pseudomonas
cepacia, naturally produced compound, storage temperature, Fragaria $\times$ ananassa

Abstract. Postharvest treatment with pyrrolnitrin (250 mg-liter $\left.{ }^{-1}\right)$ and low storage temperatures delay postharvest rot development in fall-harvested 'Tribute' strawberries (Fragaria $\times$ ananassa Duch.). Untreated fruit stored at $18 \mathrm{C}$ developed gray mold fruit rot (Botrytis cinerea) and rhizopus rot (leak) by the second day. Fruit that did not develop gray mold or leak eventually developed blue mold rot (Penicillium spp.). No rot was observed at $1 \mathrm{C}$, but gray mold and rhizopus rots developed after berries were transferred to 18C. Pyrrolnitrin delayed the appearance of the various rots by 2 to 4 days, but did not reduce the rate of rot development. Chemical name used: 3chloro-4-(2'-nitro-3'-chlorophenyl)pyrrole (pyrrolnitrin).

Shelf life of strawberries is very short because of its perishability and susceptibility to rot-causing pathogens. Botrytis cinerea Pres. \& Fr. and Rhizopus sp. were the main pathogens causing rots in strawberries shipped from California and Florida to New York (Ceponis et al., 1987). Rapid cooling of fruit to below $7 \mathrm{C}$ and storing at $0 \mathrm{C}$ with high $\mathrm{CO}_{2}$ (15\% to $20 \%$ ) atmosphere prolongs storage life (Maas, 1981). These postharvest treatments and conditions suppress disease by slowing development of infections initiated in the field. Cultural and harvesting practices can affect the incidence and intensity of sporulation of B. cinerea (Sutton et al., 1988).

In some instances, fungicide (benomyl) applications controlled pre- and postharvest gray mold rot, but the incidence of rhizopus rot increased (Jordan, 1973). We also have observed more rhizopus rot than gray mold fruit rot during storage of 'Tribute' berries

Received for publication 1 Mar. 1989. Mention of a trademark or proprietary product does not constitute a guarantee or warranty of the product by the USDA and does not imply its approval to the exclusion of other products that may also be suitable. The cost of publishing this paper was defrayed in part by the payment of page charges. Under postal regulations, this paper therefore must be hereby marked advertisement solely to indicate this fact.

Research Horticulturist.

Research Plant Pathologist.

${ }^{3}$ Research Chemist, Western Regional Research Center, USDA, ARS, Albany, CA 94710.

${ }^{4}$ Chemist, Western Regional Research Center, USDA, ARS, Albany, CA 94710

${ }^{5}$ Plant Physiologist. treated with combinations of benomyl, captan, and iprodione (F.T., unpublished data). after 1 day and were removed before photography.
The possibility of increased fungicide tolerance in the fungi (Spotts and Cervantes, 1986) and increased restrictions on pesticide usage by regulatory agencies (Board of Agriculture, National Research Council, 1987) necessitate the exploration of alternative postharvest disease control methods, such as biocontrol.

Antibiosis plays an important role in microbial interaction in various ecosystems. Microorganisms used for biocontrol of plant diseases produce antimicrobial substances such as antibiotics, bacteriocins, siderophores, or volatiles (Fravel, 1988). In some cases, purified antibiotics are used as a pesticide to control plant diseases.

Recently, Janisiewicz and Roitman (1988) reported that Pseudomonas cepacia Burkh. isolated from apple leaves has high antagonistic activity toward Penicillium expansum Lk. \& Thorn., B. cinerea, and Mucor sp. in in vitro tests and on apples and pears when applied after harvest. A compound isolated from $P$. cepacia also was effective as an antifungal agent and was identified as pyrrolnitrin, a secondary metabolite. The objective of this study was to examine pyrrolnitrin in

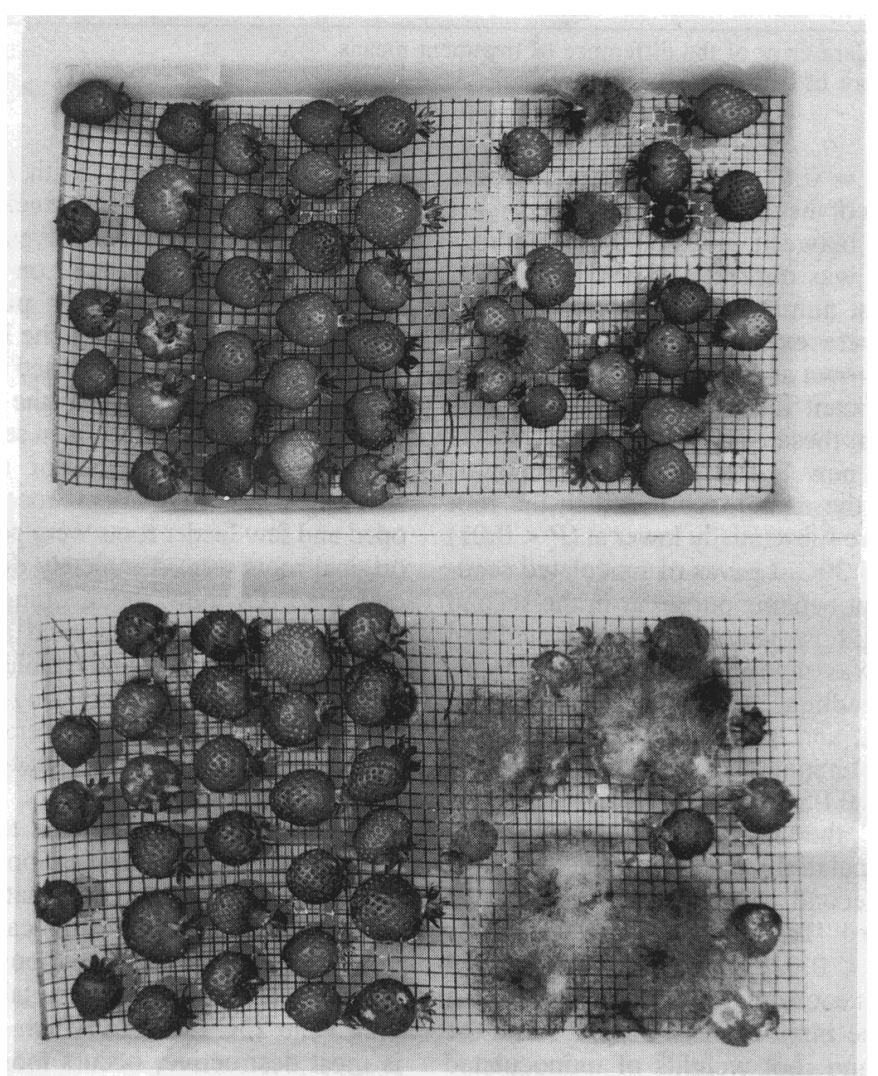

Fig. 1. Strawberries stored at 18C for 2 (top) or 4 days (bottom) (Expt. 1). Fruit were dipped in 250 $\mathrm{mg}$ pyrrolnitrin/liter (left) or in water (right) before storage. Several fruit in top right developed rot 


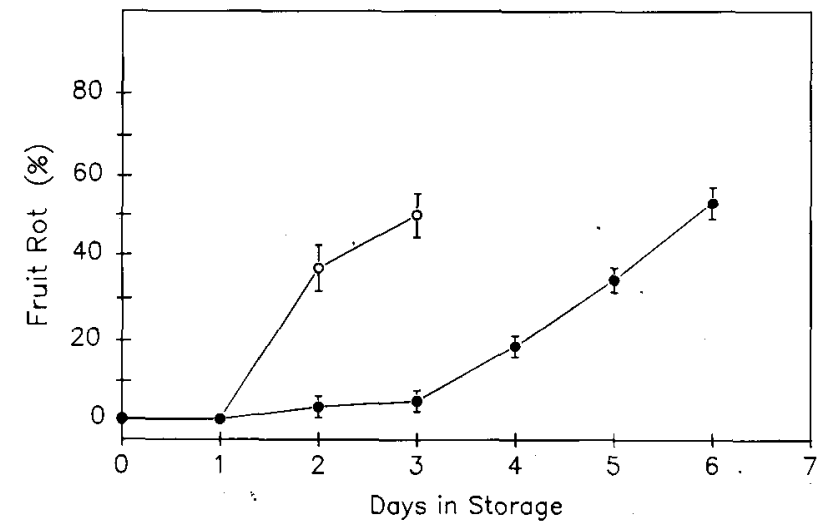

Fig. 2. Effect of pyrrolnitrin on rot development on 'Tribute' strawberry stored at room temperature (Expt. 1). Fruit were dipped in water $(\bigcirc-\bigcirc)$ or $250 \mathrm{mg}$ pyrrolnitrin/liter $(\mathbf{O}-\mathbf{0})$ and stored at $18 \mathrm{C}$. Each point represents the mean of five replicates \pm SE.

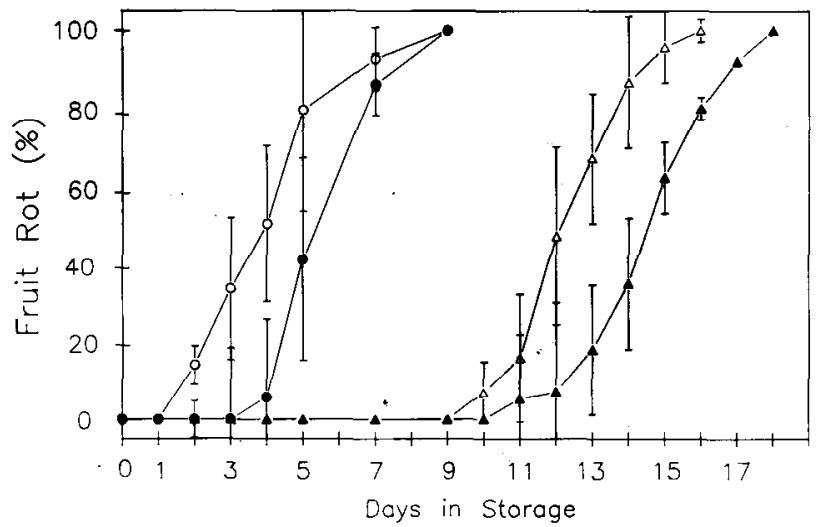

Fig. 3. Effect of pyrrolnitrin treatment and 7-day storage at $1 \mathrm{C}$ on rot development on strawberry fruit (Expt. 2). Fruit were dipped in water (open symbols) or $250 \mathrm{mg}$ pyrrolnitrin/liter (closed symbols) and stored at $18 \mathrm{C}$ (circle symbol) or for 7 days at $1 \mathrm{C}$ and then transferred to $18 \mathrm{C}$ (triangle symbol). Bars indicate $\mathrm{LSD}, P=0.05$.

relation to postharvest fruit rot in strawberries.

Pyrrolnitrin was isolated from $P$. cepacia grown in a minimal salts broth (Elander et al., 1968) in shake culture for 7 days at 27C. Pyrrolnitrin was extracted with acetone from cells after centrifugation and sonication. The resulting mixture was recentrifuged, the supernatant aqueous acetone solution separated, the acetone removed at reduced pressure, and the remaining aqueous residue lyophilized. The crude extract was stirred in methanol, concentrated to a small volume, refiltered through a $0.45-\mu \mathrm{m}$ Millipore filter, and purified by reversed phase HPLC $[21.4 \times 250 \mathrm{~mm}$ Rainin Dynamax C18 column eluted with 3 acetonitrile : 2 water $(\mathrm{v} / \mathrm{v})]$. The fraction that appeared at 9.5 to $12.5 \mathrm{~min}$ was collected and rechromatographed on a silica column eluted with 1 chloroform : 1 hexane $(\mathrm{v} / \mathrm{v})$. The peak eluted at 13.5 min was collected, the solvent removed, and the residue recrystallized from chloroform-hexane to give pure pyrrolnitrin, melting point 124 to $125 \mathrm{C}$; literature mp 124.4C (Arima et al., 1964). Spectroscopic measurements (UV, MS, and ${ }^{1} \mathrm{H}$ and ${ }^{13} \mathrm{C}$ NMR) agreed with reported data confirming the identity of pyrrolnitrin.

Dormant day-neutral 'Tribute' strawberry plants were set $25 \mathrm{~cm}$ apart on narrow raised 1988. White-on-black polyethylene mulch (VisQueen Film Products, Ethyl Corp., Richmond, Va.) was laid over the bed. Water was provided with drip irrigation, and soil moisture was maintained near soil capacity throughout the growing season. Runners, flowers, and fruit were removed until midAugust. Starting in late August, plants were sprayed to drip with benomyl (Benlate 50 WP; $0.38 \mathrm{~kg}$ a.i./ha) and captan (Captan 50 WP; $1.50 \mathrm{~kg}$ a.i./ha) at weekly intervals using a backpack sprayer. Weekly harvest of ripe fruit began in early October, usually 2 days after a fungicide application. Bruised and rotten fruit were discarded.

In the first of two experiments, five replications of 20 to 28 fruit were dipped in water or in a solution of $250 \mathrm{mg}$ pyrrolnitrin/ liter for $30 \mathrm{sec}$, then stored under high humidity at room temperature $(\approx 18 C)$. Data were recorded as a percentage of fruit affected in each replication until $50 \%$ of the square means procedure of the SAS GLM.

The second experiment was a completely randomized factorial design with five replications. Factors were storage conditions (18 $\pm 2 \mathrm{C}$ continuously or at $1 \pm 1 \mathrm{C}$ for 7 days and then transferred to $18 \pm 2 \mathrm{C}$ ). A repli- beds near Kearneysville, W. Va., in May berries had rot and were analyzed by the least cate consisted of 10 to 12 healthy fruit.

Fruit were dipped for $30 \mathrm{sec}$ in water or in a solution of $250 \mathrm{mg}$ pyrrolnitrin/liter and individually placed on a wire mesh screen suspended in an incubation box. The bottom of the box was covered with water to assure high humidity. Data were recorded as a percentage of fruit affected in each replicate and analyzed for significance of difference between two groups of data (t test, $P=0.05$ ) using the SAS GLM.

Fruit rots developed rapidly under $95 \%$ $\mathrm{RH}$ and at 18C (Figs. 1 and 2). More than $35 \%$ of fruit developed decay by the second day. Postharvest pyrrolnitrin dip inhibited growth of rot-causing organisms for 3 days. Gray mold fruit rot and rhizopus rot developed the fourth day in storage. Blue mold rot eventually developed in fruit that did not develop a gray mold or rhizopus rot early in storage. Although the storage conditions favored the growth of rot-causing organisms, the rapid postharvest rot development observed in this study indicated that the weekly fungicide applications did not markedly suppress fungal infection in the field. The incidence of fruit decay observed in the study was within the range reported by Pritts et al. (1987), who noted that 'Scott' and 'Earliglow' fruit had $5 \%$ to $20 \%$ moldy berries by the second day after removal from 4 days of cold storage.

In the second study, pyrrolnitrin and low temperature storage delayed fruit rot development (Fig. 3). Nearly 15\% of untreated fruit at room temperature developed rot by the second day. The postharvest pyrrolnitrin dip delayed the onset of rot until the fourth day. After rot became visible, pyrrolnitrin did not affect the rate of rot development (percentage of fruit rotted/day) (t test, $P=$ 0.05 ; the slope of decay curves at the linear portion).

The appearance of B. cinerea, Rhizopus spp., and Penicillium spp. was inhibited during storage at $1 \mathrm{C}$ (Fig. 3). Once removed from low temperature to $18 \mathrm{C}$, untreated fruit remained rot free for more than 2 days and did not develop rots as rapidly as did fruit kept continuously at $18 \mathrm{C}$. More than $90 \%$ of fruit remained rot-free for 3 days. Fruit that had received a postharvest pyrrolnitrin treatment remained $90 \%$ rot-free for 5 days at room temperature. However, the rot development rate was unaffected by pyrrolnitrin (t test, $P=0.05$ ) and was similar to that observed in fruit kept continuously at 18C.

Biological agents rarely eliminate disease, but generally reduce spoilage to acceptable levels. In a preliminary field test, applications of various antagonists to strawberry plants and to fruit after harvest reduced gray mold rot, but increased other types of rot (W.J.J., unpublished data). Furthermore, considerable variation among replicated plots was observed. We showed in this study that a product isolated from a biocontrol agent successfully suppresses pathogenic organisms in strawberry fruit. Extensive field and postharvest storage tests are needed to assess the commercial feasibility of the treatments. 


\section{Literature Cited}

Arima, K., N. Iwanaka, M. Kousaka, A. Fukuta, and G. Tamura. 1964. Pyrrolnitrin, a new antibiotic substance, produced by Pseudomonas. Agr. Biol. Chem. 28:575-576.

Board of Agriculture, National Research Council. 1987. Regulating pesticides in food-The Delaney paradox. National Academy Press, Washington, D.C.

Ceponis, M.J., R.A. Cappellini, and G.W. Lightner. 1987. Disorders in sweet cherry and strawberry shipments to the New York market, 1972 1984. Plant Dis. 71:472-475

Elander, R.P., J.A. Mabe, R.H. Hamill, and M. Gorman. 1968. Metabolism of tryptophans by
Pseudomonas aureofaciens. Applied Microbiol. 16:753-758.

Fravel, D.R. 1988. Role of antibiosis in the biocontrol of plant diseases. Annu. Rev. Phytopathol. 26:75-91.

Janisiewicz, W.J. and J. Roitman. 1988. Biological control of blue mold and grey mold on apples and pears with Pseudomonas cepacia. Phytopathology 78:1697-1700.

Jordan, V.W.L. 1973. The effects of prophylactic spray programs on the control of pre- and postharvest diseases of strawberry. J. Plant Pathol. 22:67-70.

Maas, J.L. 1981. Postharvest diseases of strawberry, p. 329-353. In: N.F. Childers (ed.). The
strawberry-Cultivars to marketing. Horticultural Publications, Gainesville, Fla.

Pritts, M.P., J.A. Bartsch, K.A. Worden, and M.C. Jorgensen. 1987. Factors influencing quality and shelf life of strawberry cultivars in the eastern United States. Adv. Strawberry Production 6:1417.

Spotts, R.A. and L.A. Cervantes. 1986. Populations pathogenicity, and benomyl resistance of Botrytis spp., Penicillium spp., and Mucor piriformis in packinghouses. Plant Dis. 70:106108.

Sutton, J.C., T.D.W. James, and A. Dale. 1988. Harvesting and bedding practices in relation to grey mold of strawberries. Ann. Applied Biol. 113:167-175. 